\title{
EXPOSURE AT DEFAULT. THE PROBLEM OF ITS ESTIMATION IN THE CONTEXT OF CAPITAL REQUIREMENTS
}

\section{Pawel Siarka}

\begin{abstract}
Credit risk analysis is largely based on the principles set out by the Basel Committee. Next to the probability of default and recovery rate, one of the most important elements of risk management systems is the value of the exposure at default. This paper presents the issue of EAD (Exposure at Default) estimation with respect to both balance sheet and off-balance sheet items. The author refers to the problem regarding the assessment of EAD forecast quality. He presents the results of the simulations conducted for the most common retail portfolios. The results show that the expected value of the exposure at default is significantly lower than the balance value at the moment of capital requirement calculation. This leads to the conclusion that the approach recommended by the Basel Committee, based on the current book value of the exposure, may result in the overestimation of EAD. The paper contains the proposal of the method which was leveraged for retail products (cash loans, car loans, mortgage loans).
\end{abstract}

Keywords: credit risk, EAD, PD, LGD.

JEL Classification: C13, C16, D81, G21, G32, G3.

DOI: $10.15611 / \mathrm{me} .2014 .10 .05$.

\section{Introduction}

The Basel Committee in its recommendations under Basel II [Basel... 2006] referred to the minimum capital requirement for covering potential losses on individual risks. With respect to credit risk in accordance with the advanced method, the minimum capital requirement has been determined as a function of three key elements: the probability of default (PD), the percentage loss of the exposure (LGD, Loss Given Default) and the value of the exposure at the time of an event of Default (EAD, Exposure at Default). In the literature of risk management there are many studies on the estimation of PD or LGD, however the issue of EAD is still little explored by researchers.

Pawel Siarka

Ernst \& Young

E-mail: pawel.siarka@gmail.com 
A bank, for all its loan portfolios, calculates the revenues and costs associated with their maintenance. The positive profitability of the loan portfolio means that revenues are higher than the costs. One of the main costs is the credit risk that affects the profit and loss account and, consequently, the bank's equity. Hence, the bank is interested in estimating the amount of defaulted loans. For this purpose a PD (Probability of Default) is leveraged. However, information on the average value of PD is not sufficient to assess the extent of the risk that the bank may incur. Banks conduct the recovery of debts, and therefore a part of the overdue debt is recovered. Hence the real loss (expressed as the percentage value of the exposure) is particularly important. This value refers to the LGD (Loss Given Default). In order to present the loss in nominal terms, it is necessary to estimate the value of the exposure at the time of the appearance of default (EAD).

EAD is one of the most important elements of the recommended approaches under Basel II. It is defined as the gross value of the exposure, expressed in the national currency at the time of the occurrence of the event of default. This item refers not only to the value of the outstanding (principal), but also takes into account the accrued and unpaid interests, as well as other fees that increase the total balance value. Thus, for loans with a specific repayment schedule, it is necessary to calculate the total balance value including the principal account, the account of accrued and unpaid interest, penalty interest, payment reminders, and other fees associated with loan maintenance. Another approach is used in relation to exposures that do not have a schedule, such as credit lines. In this case, the most commonly used approach leverages the balance value of the exposure increased by its expected growth within the granted credit limit. The credit limit is recognized as an off-balance sheet item.

In accordance with the IRB approach (Advanced Internal Rating-Based Approach), the bank is required to estimate the CCF (Credit Conversion Factor). This parameter informs us about the percentage of the off-balance sheet item which will be incorporated in the capital requirements calculation. This is why the CCF affects the value of the exposure at default. Hence the CCF presents the expected utilization of the credit line until the event of default.

In the case of retail credit exposures when the full amount of the loan is paid at once, the CCF approach in not applicable. However, it is still a key element to estimate the potential loss, and the exposure at default. Expected loss is calculated as the product of the probability of default, LGD and 
EAD. The last parameter can be interpreted as a forecast of the credit exposure that can default within the next 12 months.

In the literature, there are few studies addressing the issue of estimating the credit exposure at default. Araten and Jacobs [2001], analyzed the loans granted between 1985 and 2000. They noticed that companies whose economic conditions started to deteriorate were more likely to use the whole granted credit limits. Also, Jimenez, Lopez, and Saurin [2007], found that the factors affecting the level of utilization of the credit line are the current credit risk and the length of the cooperation with the bank. Other macroeconomic factors seemed not to be so relevant. An innovative approach to the estimation of EAD was presented Moral [2006]. He referred to these three methods. First, the leveraged loan principle used for minimizing the sum of squared differences between the estimated and actual values for the whole portfolio. Another implemented approach leveraged a weighted average, where the weights were the undrawn credit lines. The author also noted that the potential losses resulting from the underestimation of EAD can be much higher than in the case of overestimation. This is why he was analyzing asymmetric loss functions which in his opinion can help to calculate capital requirements in a more reliable way. Kupiec [2007], focused in his research on the problem of the increase of risk parameters, including EAD, under adverse economic conditions. It turned out that adverse macroeconomic conditions may cause a significant growth of credit exposure. In his opinion, this is a result of liquidity deterioration during an economic downturn. This thesis was also proved by Kaplan and Zingales [1997]. Kupiec referred to the correlation between the PD, LGD and EAD. Agarwal, Ambrose and Liu [2006], in their study focused on retail loans. They examined the relationship between the scoring result and the level of undrawn credit line. The problem of EAD estimation regarding credit cards was presented by Min Qi [2009]. He showed that the scoring result, the number of borrower's bank accounts and the number of credit inquiries impact on the use of the granted credit line. Also Vytautas [2008], presented a range of empirical results obtained for retail loans. In his work he pointed out that retail loans are not explored enough. He also emphasized that the rigid rules imposed on banks by the Basel Committee do not encourage the implementation of alternate EAD models.

The purpose of this article is to present the issue of EAD estimation, which is one of the foundations of risk management systems in banks. The authors wanted to present an alternate approach which differs from the method recommended by the Basel Committee. The Basel approach 
assumes that EAD cannot be lower than the current book value of the exposure. The presented study verifies this assumption against the background of retail loans. Thus, the hypothesis regarding installment loans i.e. that the expected value of EAD is lower than the current book value, was verified.

This article starts with an introduction and literature review. The next part presents selected statistical methods useful for EAD estimation and the approach to the forecast accuracy assessment. Next, the results of simulation analysis regarding retail loans are presented. In this chapter the results of cash loans, car loans and mortgage loans are compared. Based on the results, the authors presented the expected percentage decrease of the value of the exposure within the period between the capital requirements calculation and the default occurrence.

\section{The credit conversion factors in the process of EAD calculation}

In accordance with the provisions of the New Basel Capital Accord, EAD cannot be lower than the current book value of the loan. This approach is quite conservative as the loss horizon is assumed to be 12 months. For retail loans it can be shown that the real value of the EAD is often lower than the current book value.

The Basel Committee recommends that each bank should have a written, and approved by the Board rules concerning EAD, estimation. These rules should take into account both balance sheet and off-balance sheet items. In addition, these procedures should apply to homogeneous portfolios with a particular emphasis on those financial instruments where the borrowers have the right to draw a credit line. Moreover, EAD should be calculated at the exposure level. In addition, it is recommended to study the impact of the macro factors or business cycle on particular portfolios. The banks are also obliged to monitor the credit risk based on daily data and asses the quality of risk forecasts. The latter procedure is called back-testing, and is a key part of the risk management process.

There are two approaches to EAD calculation depending on the type of the loan schedule. The first concerns the exposures that have a repayment schedule (e.g. monthly payments) and the balance of the loan decreases with each repayment. The second approach relates to exposures that payments are made at the end of the loan life or are done in other ways stated in the loan agreement. In the latter situation, the loan balance may constantly change due to the lack of fixed schedule. An example of this type of financial instrument is a credit line. The borrower has the right to draw on the 
line of credit up to the maximum loan balance. The part of the line which is drawn stays in the bank's balance sheet. The rest is an off-balance sheet item. These items are particularly important from the risk management point of view. According to the agreement, the bank is obliged to provide the funding to the client at his/her request and there are no additional conditions. It is also common that the loan tranches are available only when some conditions are met. This can depend, for example, on the progress of the funded investment.

According to the New Basel Capital Accord, the off-balance sheet items require the calculation of the credit conversion factors $(\mathrm{CCF})$ under the risk management process. These factors help to predict the most probable values of the exposures for a given period of time. It also should be noted that there are some financial instruments incorporating characteristics appropriate for the first and second above-mentioned group. An example might be a mortgage loan, which is typically payable in installments. However some loan tranches may be assumed to be paid on time. Thus, the off-balance sheet items should be addressed in order to estimate the expected value of the credit exposure in the case of an unexpected default event. The EAD can be calculated for given instrument $f$ as follows:

$$
E A D(f)=C C F(f) \cdot \operatorname{Limit}(f),
$$

where Limit is the maximum loan balance granted by the bank, and the $C C F$ is the credit conversion factor representing the expected percentage of utilization of the credit line.

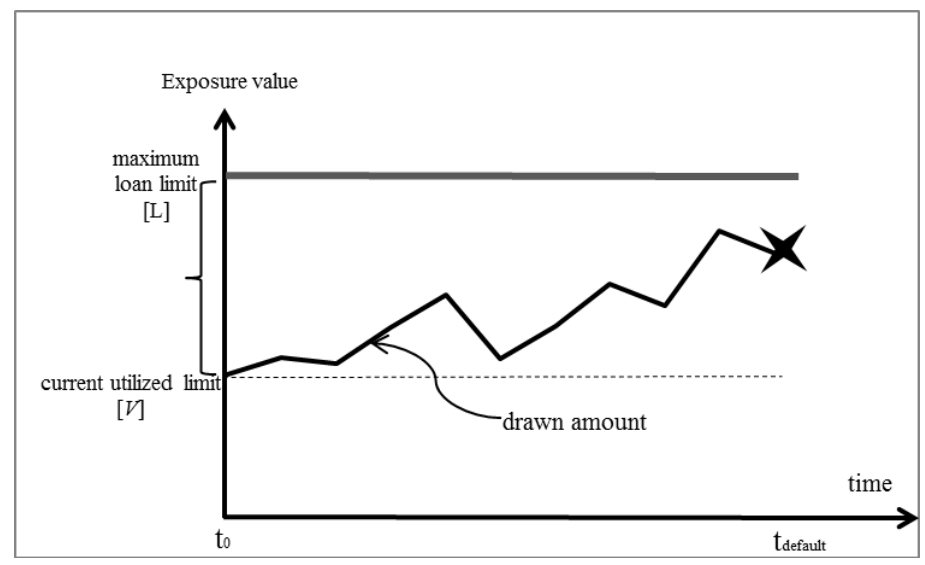

Fig. 1. Limit utilization in time up to the default even

Source: author's work. 
Another approach to EAD calculation takes into account the actual balance value of the loan. Thus, the EAD can be calculated according to the following formula:

$$
E A D(f)=\text { Balance }(f)+L E Q \cdot U n_{-} \text {Limit }(f),
$$

where Balance is the actual balance value, $L E Q$ is the expected percentage of the unused credit line (Un_Limit), which is going to be utilized within the given period of time.

The problem of calculating the EAD represents Figure 1. To estimate the exposure value in the future at time $t_{\text {default }}$, the current balance value at time $t_{0}$ is required. The credit limit and LEQ are also needed.

Suppose that the default event occurs in the future at time $t_{\text {defaul }}$. The capital requirements are calculated before that at $t_{0}$. Then EAD for the given $i$-th exposure can be estimated as a function of a granted limit $L$ and its actual utilized part $V$ :

$$
E A D_{i}=V_{i}\left(t_{0}\right)+L E Q_{i} \cdot\left(L_{i}\left(t_{0}\right)-V_{i}\left(t_{0}\right)\right) .
$$

The above equation leads to the $L E Q$ formula:

$$
L E Q_{i}=\frac{V_{i}\left(t_{\text {default }}\right)-V_{i}\left(t_{0}\right)}{L_{i}\left(t_{0}\right)-V_{i}\left(t_{0}\right)}
$$

or respectively

$$
L E Q_{i}=\frac{\frac{V_{i}\left(t_{\text {default }}\right)}{L_{i}\left(t_{0}\right)}-\frac{V_{i}\left(t_{0}\right)}{L_{i}\left(t_{0}\right)}}{1-\frac{V_{i}\left(t_{0}\right)}{L_{i}\left(t_{0}\right)}} .
$$

Until the default occurs, the value of the exposure is unknown. This is why the estimation methods are based on the historical data. The current value of the exposure and the maximum loan limit determine the credit conversion factor. Figure 2 illustrates the idea of CCF calculation. In this case the default has already occurred, so EAD is already known.

During the calculation of loan EAD, the moment of default and the utilization of the loan are unknown. This situation is shown in Figure 3. This is why a wide set of different scenarios of utilization are considered. The maximum credit loss is limited to the granted credit line. The time horizon for the expected default occurrence shall be assumed by the bank. Usually 
banks consider a 12-month horizon which is in line with the New Basel Capital Accord concept and represents the full financial reporting period.

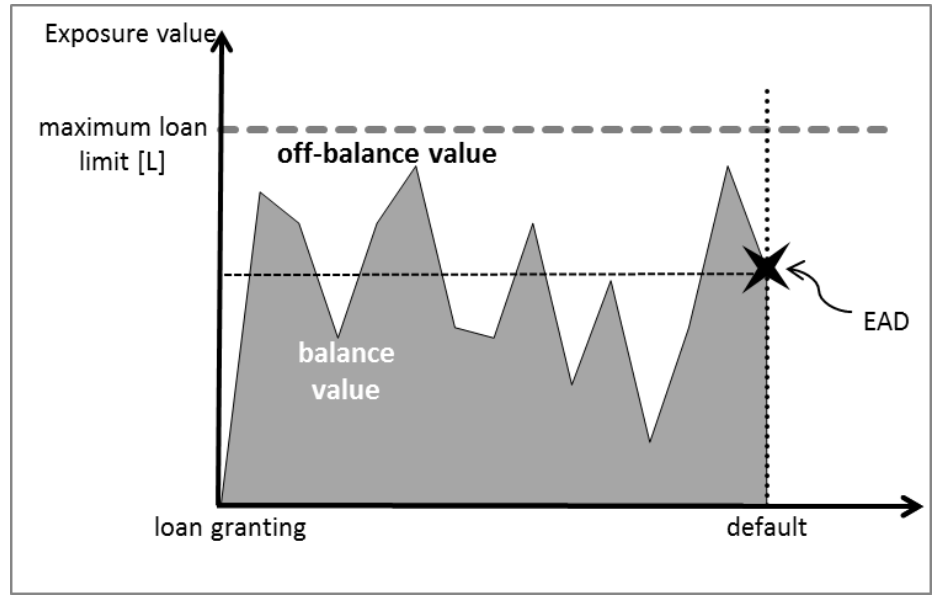

Fig. 2. EAD - ex-post analysis

Source: author's work.

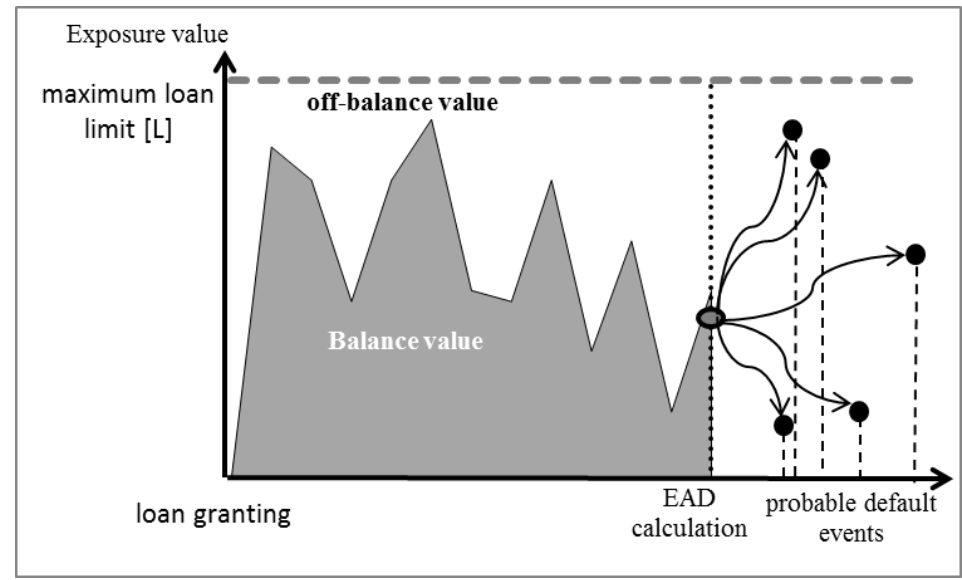

Fig. 3. EAD - scenario analysis

Source: author's work.

The calculation of CCFs based on the historical data depends on $t_{0}$. Having the default date, it is crucial for the ex-post analysis to determine it. The utilization rate may significantly vary for a period of 1,3 or 6 months before a default. This issue is presented in Figure 4. The lower graph shows the financial condition which systematically deteriorates. At the same time 
the loan utilization increases, which is commonly observed by the banks. The negative correlation between the company's financial condition and loan utilization often results from increasing liquidity needs. When the company's condition falls below a certain threshold level the default appears. It should be emphasized that the increase in the utilization depends on the moment according to which the growth is analyzed. Therefore in Figure 4 , the historical conversion factor calculated for time $t_{1}$ will be higher than that calculated for time $t_{2}$.

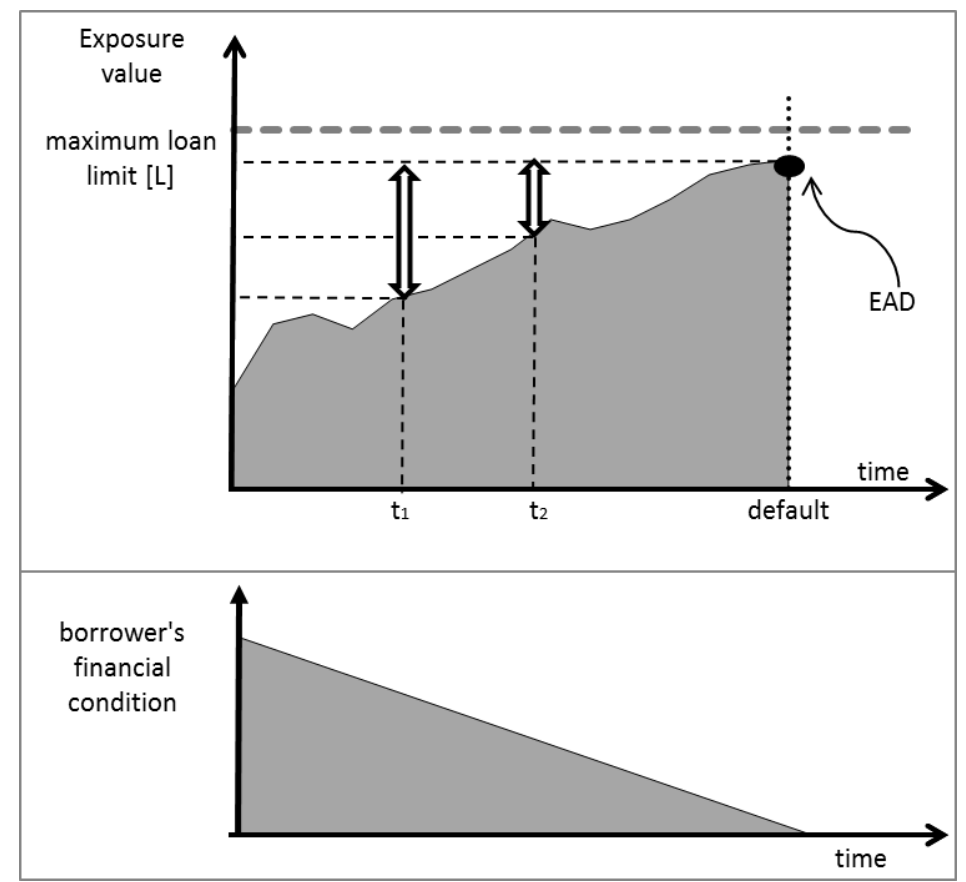

Fig. 4. The relationship between the time before default and utilization rate

Source: author's work.

The issue of specifying the initial moment prior to the default event is crucial and impacts on the results. Figure 4 shows that the conversion factors for the given periods $\left(t_{1}, t_{2}\right)$ may vary significantly. One possible solution is to use a fixed period (time window) for the analysis. This approach uses the exposure value at a specified moment period before the default e.g. 12 months. This idea is shown in Figure 5. The lower axis represents the time where the default events are marked, The upper axis represents the 
moment used for calculating the credit line utilization. In the presented example, a constant time lag (12 months) was leveraged.

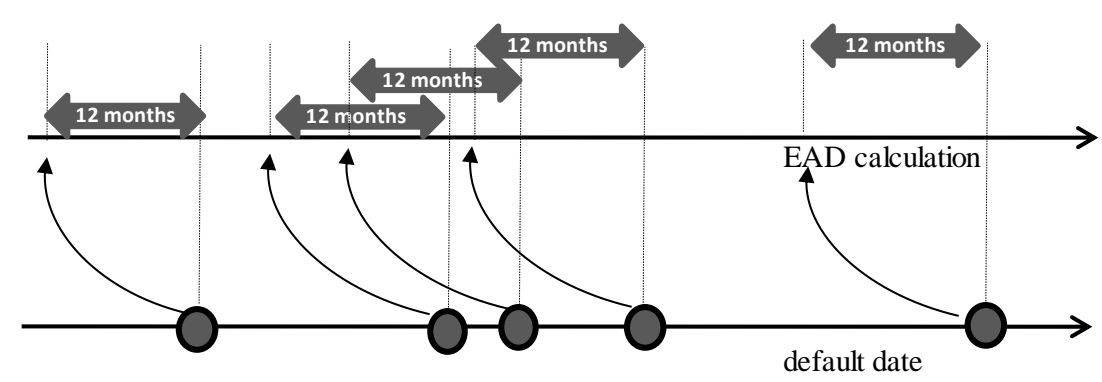

Fig. 5. EAD calculation with "fixed time window"

Source: author's work.

The 12 months 'fixed time window' was picked arbitrarily and shorter periods are also acceptable, however this should be supported by the relevant analyses of historical data. The main disadvantage of the presented approach is a difficult-to-meet assumption regarding the 'fixed-time window'. It is difficult to expect that all defaults appear exactly after the assumed period of time. This disadvantage does not have the cohort method. Under this approach, conversion factors are calculated using exposure values at the same moment for all loans. The idea of this method is presented in Figure 6. In this example, all loans which defaulted in the same year take their balance value on the same day (e.g. 1st January).

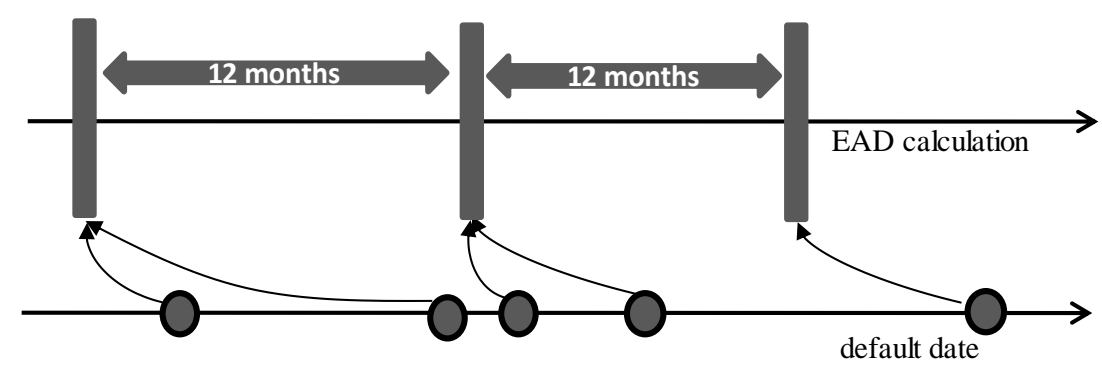

Fig 6. EAD calculation - cohort approach

Source: author's work.

When a borrower increases his/her debt drifting towards insolvency, the credit conversion rate received with this method will be lower than that estimated using a fixed 12-month "fixed-time window". 
An alternative approach to the presented above methods is based on the average outstanding over time. This is a modification of the first method based on the 'fixed time window'. For each exposure there are conducted several CCF calculations. This idea is presented in Figure 7. In the example it is assumed that for each defaulted exposure there are three calculations made. For an annual loss horizon, the maximum "window analysis" should not exceed 12 months. It is convenient to estimate EAD based on 12 results achieved for the last months before the default.

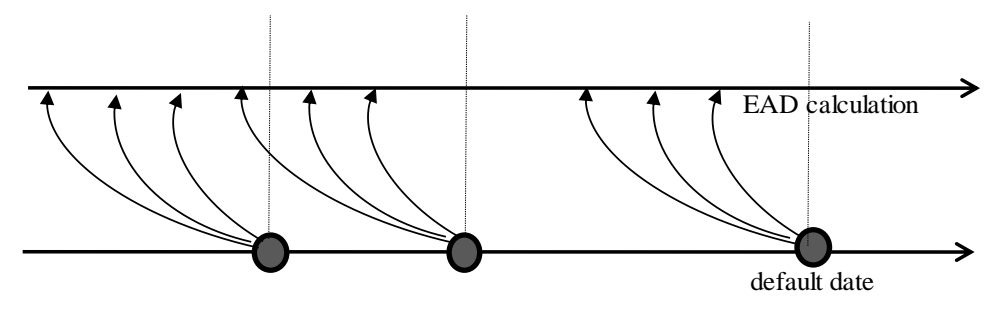

Fig. 7. EAD calculation - 'mixed' approach

Source: author's work.

In line with the above mentioned approach, the credit conversion factor can be calculated as the average based on monthly observations for $i$-th exposure according to the following formula:

$$
L E Q_{i}=\frac{\sum_{t=1}^{12} L E Q_{i, t}}{12} .
$$

\section{Back-testing of EAD}

A comprehensive forecasting process of the exposure value at default needs an assessment of the quality of the estimates. EAD forecast accuracy can be examined using an ex-post forecast error. To do this, it is necessary to leverage all the forecasts done at the exposure level. It is also required to possess the actual values which were observed at the default event.

Based on the forecast errors, the average forecast accuracy is calculated in the following form:

$$
\Psi=\frac{1}{n} \sum_{i=1}^{n}\left|\frac{E A D_{i}-E A D_{l}}{E A D_{i}}\right|,
$$

where $n$ is the number of defaulted exposures and $E A D_{l}$ is the forecast of $E A D_{i}$. 


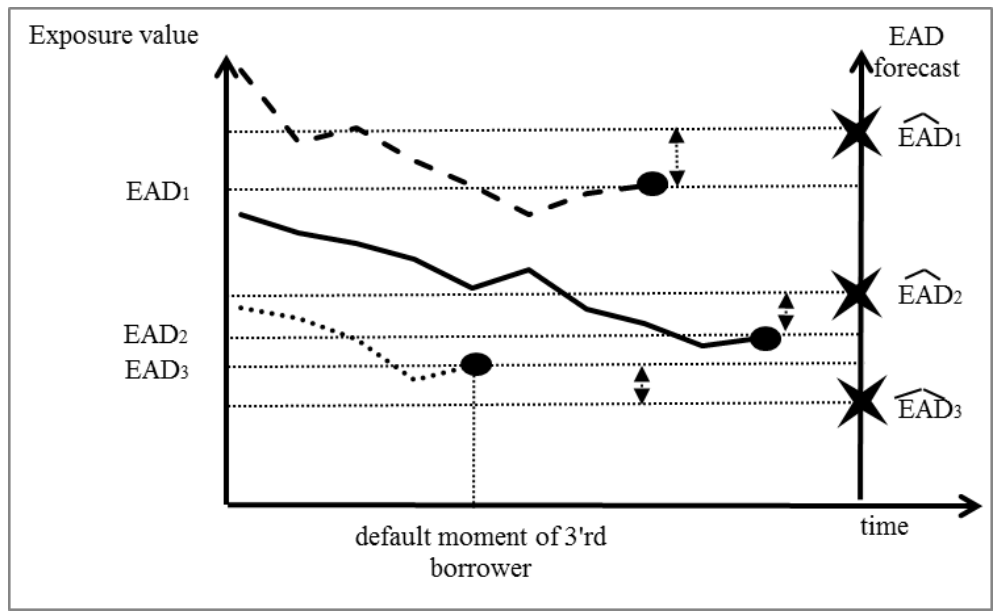

Fig. 8. EAD - back-testing

Source: author's work.

This idea is illustrated in Figure 8. It shows three credit exposures for which the changes of its value before the default are observed. The right axis presents the EAD forecasts, while the left axis shows the actual value of EAD. The differences between these two values are leveraged to calculate the forecast error.

\section{Simulation analysis for retail loans}

When the credit exposures are repaid in equal monthly installments and granted in one tranche, the issue seems to be quite straightforward. However, in accordance with the New Basel Capital Accord, the EAD may not be lower than the current book value. The effect of a reduction of the outstanding due to possible subsequent repayments is completely ignored. The supporters of this approach argue that the penalty interests offset the potential repayments before the occurrence of the default. The results of the presented below simulation proved that the Basel approach may lead to an overestimation of the exposure value.

Figure 9 presents an example of the exposure value for a loan repaid by the borrower according to the schedule. The loan outstanding is decreasing due to the repayments, however the accrued interests raise the loan value between the maturities of the following installments. Hence the value of the loan paid in installments has a unique shape in the time- cyclical increases and decreases (Figure 9). 


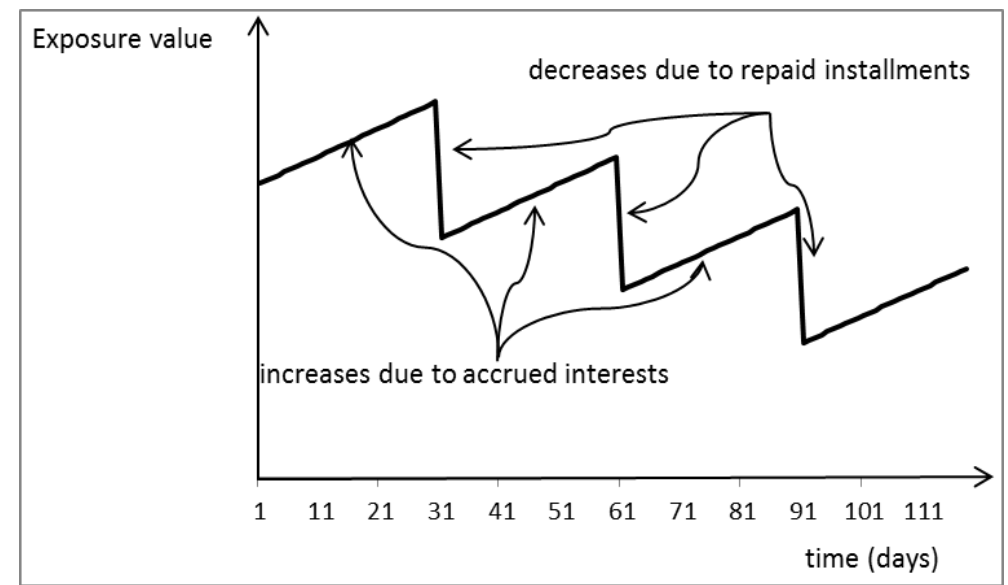

Fig. 9. Exposure value for loans paid in installments

Source: author's work.

In order to analyze the EAD values, a simulation analysis was conducted. The goal was to measure the percentage decrease of the exposure value between the moment of analysis and the moment of the expected default. For the purposes of the analysis, it was assumed that the probability of default calculated in a 12-month horizon is known. It was also assumed that the defaults occur uniformly across all 12 months. The leveraged default definition was consistent with the Basel Committee approach [Basel... 2006]. This means that the exposure was considered as defaulted when its DPD (Days Past Due) exceeded 90 days. Thus, the 3-month period prior to the insolvency does not include any repayments. However the contractual interests, as well as the penalty interests, are increasing the value of the exposure.

The simulation analysis was leveraged to calculate the distribution function of measure $Z$ presenting the percentage decrease of the exposure value within the time between the analysis and default event:

$$
Z=\frac{E \ddot{A} D}{E A D},
$$

where $E \ddot{A} D$ is a simulated value of the exposure at the moment of default, while $E A D$ is a book value calculated at the time of EAD analysis according to Basel II. The discrepancies between these two values shall reveal the issue concerning the EAD measurement.

The simulation analysis was carried out for three types of retail products: cash loans, car loans and mortgages. The pricing parameters regarding 
these portfolios were acquired from a bank operating in Poland. For cash loans the average value of the loan was assumed to be 5000 PLN, while the standard deviation was equal to 800 PLN. The average number of installments (monthly installments) remaining to the end of the loan life was equal to 27 with a standard deviation of 8 months. The annual interest rate for cash loans was equal to $19 \%$. The average value of car loans was 9540 PLN and the standard deviation was equal to 2100 PLN. The average number of installments remaining to the end of the loan life was 38, and the standard deviation was 10 . The interest rate of car loans was $12 \%$ per annum. In the third portfolio, mortgage loans, the average value of the loan was 85000 PLN, and the standard deviation was equal to 23000 PLN. The average number of installments remaining to the end of the loan life was 84 months with the standard deviation of 21 months.

The simulation was based on generating a random pool of defaulted borrowers. For each exposure a moment of default was randomly generated. It was assumed that the probability of occurrence of default is uniformly distributed across the year. For each loan a value of the outstanding was assigned according to a random value derived from a normal distribution function (with respect to the assumed parameters). In the next step, a full repayment schedule was calculated for each exposure, including principal and interest. For this purpose the portfolio average interest rate was leveraged, as well as the exposure value and the number of installments remaining to the end of the loan life. The number of installments remaining to the end of the loan life was determined based on the random values derived from the normal distribution function (for the given parameters regarding each portfolio).

Within the simulation it was assumed that the installments are paid on time up to the three months before the default. When the borrower stops paying the installments the interests were calculated up to the default. In this way the value of the exposure at default was calculated. The population of defaulted loans was equal to 10000 for each portfolio. For each exposure the percentage change of its value up to the moment of default was calculated. These data were leveraged to estimate the distribution function of this percentage change.

Figure 10 shows the simulation results regarding the cash loan portfolio. The average change (decrease) of the exposure value up to the default event was equal to $15.5 \%$, while the standard deviation was $17.1 \%$. 


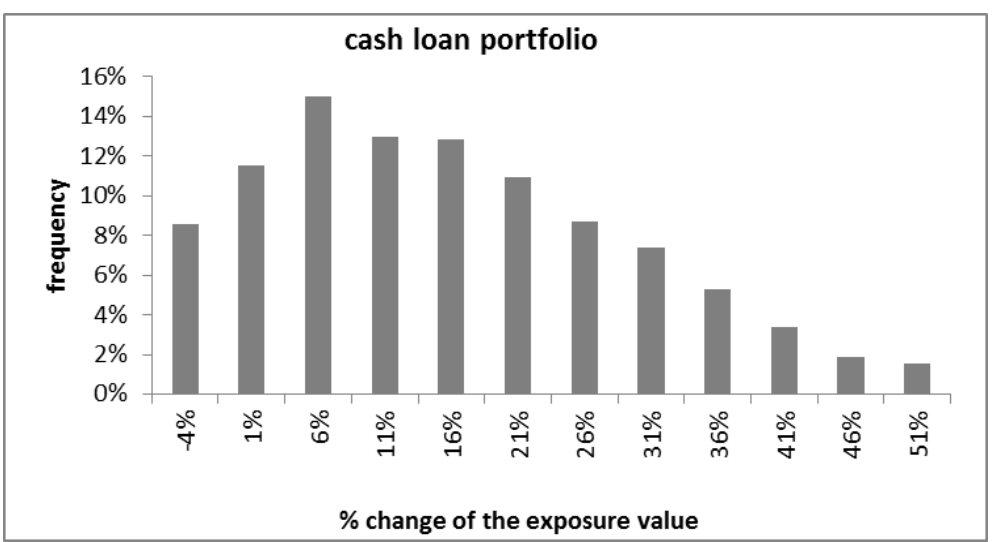

Fig. 10. Distribution of percentage change of the exposure value (cash loans)

Source: author's work.

Figure 11 presents the distribution of the percentage change of the exposure value for car loans. The average decrease of the exposure value was equal to $11.3 \%$ EAD, while the standard deviation was $11.4 \%$.

Figure 12 shows the results for the mortgage portfolio. The average value in this case was $4.3 \%$, with a standard deviation of $4.6 \%$.

The results show a significant decrease of the exposure value during the time up to the default event. The largest average decrease of the exposure value was observed for cash loans. A much smaller change was observed for car loans. The smallest change $(4.3 \%)$ refers to the mortgage portfolio.

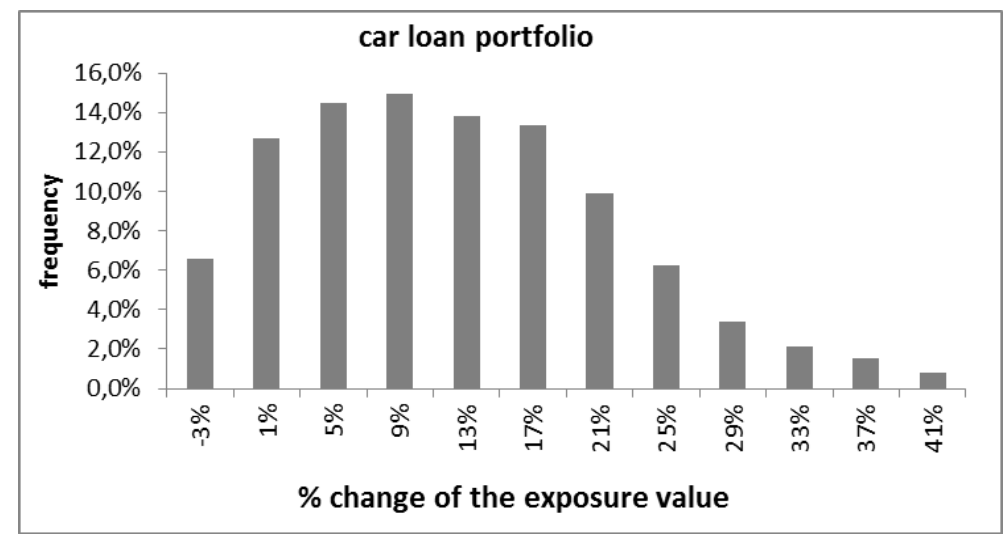

Fig. 11. Distribution of percentage change of the exposure value (car loans) Source: author's work. 


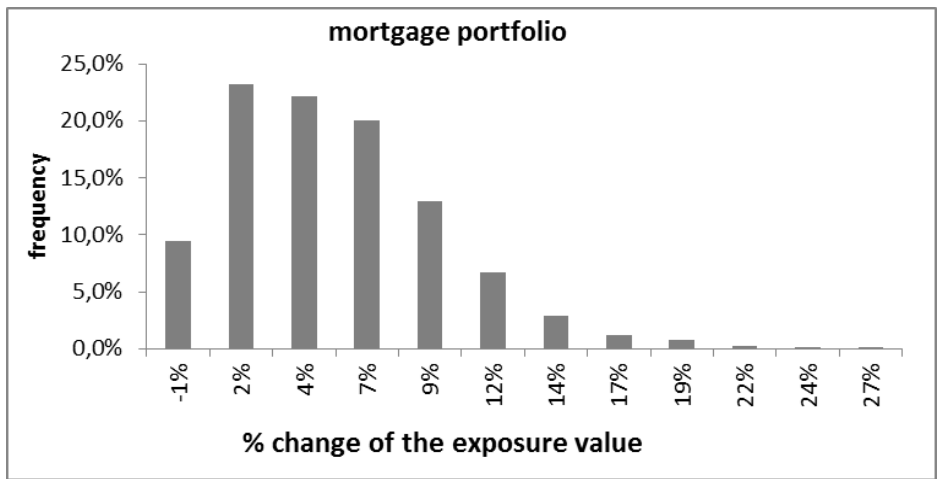

Fig. 12. Distribution of percentage change of the exposure value (mortgage loans)

Source: author's work.

It is obvious that the results are sensitive to the assumptions made for the purpose of analysis. One of the most important assumptions refers to the number of installments remaining to the end of the loan life. Thus, a sensitivity analysis was conducted regarding the changes of this parameter. For all three portfolios the simulations were performed including different values of the number of installments. Figure 13 presents the results achieved for cash loans. It shows the relations between the average decrease of the exposure value and the expected number of remaining installments. As is presented, the percentage change of the exposure value is a decreasing function of the number of the remaining installments. Thus the shorter the period to the end of the loan life, the higher the decline of the exposure value.

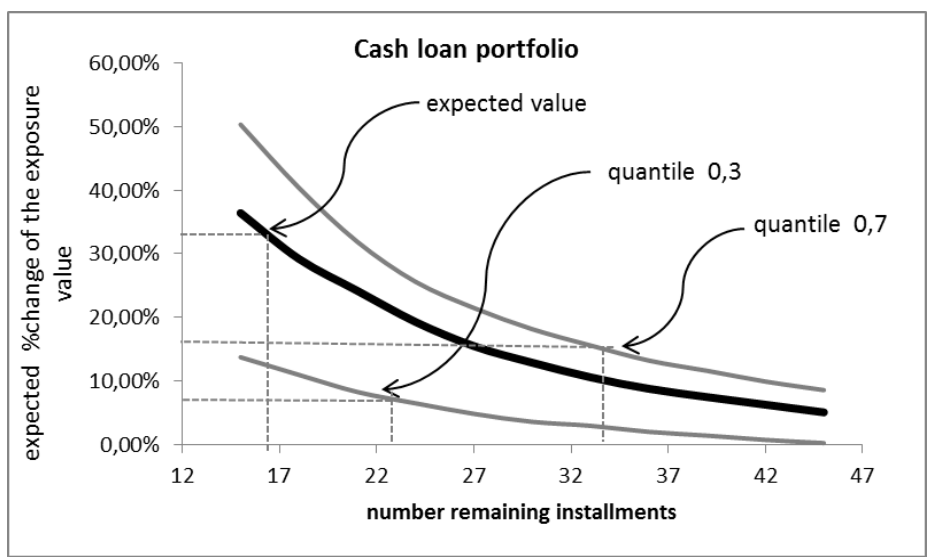

Fig. 13. Relation between the percentage change of the exposure value and the number of remaining installments (cash loans)

Source: author's work. 


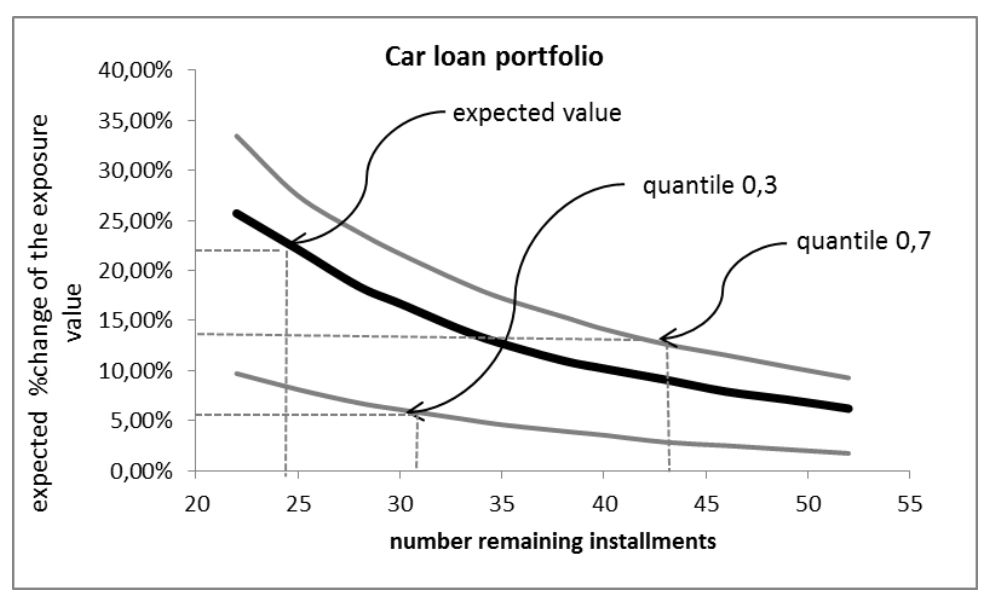

Fig. 14. Relation between the percentage change of the exposure value and the number of remaining installments (car loans)

Source: author's work.

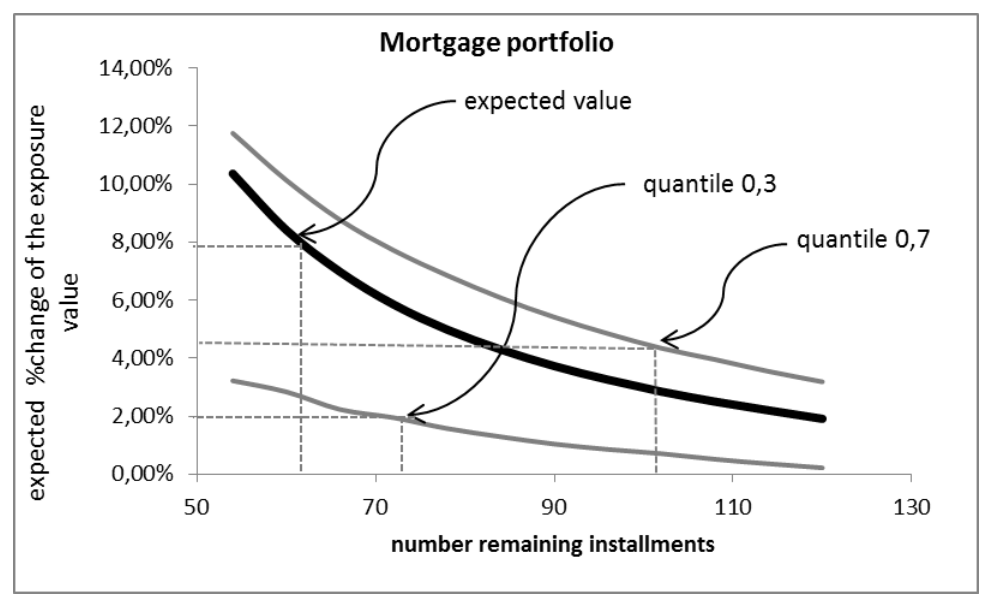

Fig. 15. Relation between the percentage change of the exposure value and the number of remaining installments (mortgage loans)

Source: author's work.

Figure 14 shows the results for the car loan portfolio. Similarly to previous results, we can observe a significant decrease of the expected exposure value for a higher number of remaining installments. However it should be emphasized that the achieved line is less inclined forming more of a flat slope compared to the cash loan portfolio. The least inclined slope was obtained for mortgage loans. There are two main factors explaining this. 
Mortgage loans are granted for the longest periods and have the lowest annual interest rates. As was presented earlier, the average interest rate for car loans was $19 \%$, while for car loans it was $12 \%$ and $6.4 \%$ for mortgage loans. It appeared that the interest rate has a significant impact on the change of the exposure value during the period before the default. This is because the accrued interests and penalty interests increase substantially the value of the exposure.

Figure 15 presents the results obtained for the sensitivity analysis regarding the mortgage portfolio. In this case, a relatively small slope of the analyzed line (expected value) can be observed.

The results show that during the time between current moment and the default event (expected within 12 months), a significant decrease of the exposure value can be observed. Hence, the simplified approach utliziling current book value which is recommended under the New Basel Capital Accord, may lead to an overestimation of EAD.

The performed simulations let us estimate the distribution functions of the percentage changes of the exposures which defaulted within the next 12 months. For each loan portfolio the result distribution was right-skewed. This is the result of the occurrence of many observations much higher than the average value. The non-symmetric shape of the distribution function highlights even more the disadvantage of the Basel simplified method.

\section{Conclusions}

The risk management process should be organized in such a way that provides the bank with the continuous ability to pay its liabilities. Credit risk is particularly important due to the size of potential losses. The expected value is typically calculated as the product of the probability of default, LGD (Loss given Default) and exposure at default. This formula is used to estimate the losses for provision purposes as well as the capital requirements. Hence, it is crucial to estimate these parameters in a reliable way. The overestimation of the parameters leads to the overestimation of provisions and unexpected loses (VaR999). So it can be concluded that the EAD calculated according to the Basel Committee recommendations is a conservative approach. A higher provision and a capital requirement will be the benefit raising the safety of the bank. Unfortunately the risk parameters are also leveraged for other purposes, where overestimation is not desirable. One example can be the process of calculating loan profitability and the process of adjusting the loan price parameters. The process of launching 
new banking products to the market also requires reliable risk estimates. Overestimated risk can lead to wrong decisions. This can cause some unjustified limitation in sales, and even lead to closing the business line due to its incorrectly calculated profitability. For these reasons it is so important to assess the risk precisely.

In this paper it was emphasized that the credit exposure value may increase substantially when the borrower's economic condition deteriorates. The Basel Committee recommendations do not allow to use EAD below the current exposure value. However, the presented results revealed that the expected decline of the credit exposure value up to the moment of default may be significant. For cash loans this can reach 17\%, while for mortgages $4 \%$.

\section{References}

Agarwal S., Ambrose B., Liu Ch. (2006). Credit Lines and Credit Utilization. Journal of Money, Credit, and Banking 38. Pp. 1-22.

Araten M., Jacobs M. Jr. (2001). Loan equivalents for revolving credits and advised lines. The RMA Journal. Pp. 34-39.

Basel Committee on Banking Supervision (BCBS) (2006). International Convergence on Capital Measurement and Capital Standards, Bank for International Settlements. Basel.

Jiménez G., Lopez J., Saurina J. (2007). Empirical Analysis of Corporate Credit Lines. Federal Reserve Bank of San Francisco. Working Paper 2007-14.

Kaplan S., Zingales L. (1997). Do investment-cash flow sensitivities provide useful measures of financing constraints? Quarterly Journal of Economics 112. Pp. 169-215.

Kupiec P.H. (2007). A Generalized Single Common Factor Model of Portfolio Credit Risk, Annual Derivatives Securities and Risk Management Conference, Federal Deposit Insurance Corporation's Center for Financial Research.

Min Qi (2009). Exposure at Default of Unsecured Credit Cards, http://www.occ.treas.gov/publications/publications-by-type/economics-working -papers/2011-2009/wp2009-2.pdf.

Moral G. (2006). EAD Estimates for Facilities with Explicit Limits. In: The Basel II Risk Parameters, Engelmann B., Rauhmeier R. (eds.). Springer. Pp. 197-242.

Shigeaki F. (2008). Credit Risk Assessment Considering Variations in Exposure: Application to Commitment Lines. http://www.imes.boj.or.jp.

Vytautas V. (2008). Estimating EAD for retail exposures for Basel II purposes. Journal of Credit Risk. Vol. 4. No. 1. 